\title{
Maternal Health Indicators of Selected Wards of Barahachhetra Municipality Sunsari Nepal
}

\author{
Sigdel $\mathrm{R}^{1^{*}}$, Lamsal $\mathrm{S}^{2}$, Badhu $\mathrm{A}^{3}$ \\ ${ }^{1}$ Assistant Professor, Department of Community Health Nursing, BPKIHS, Dharan, Nepal \\ ${ }^{2}$ Professor, Department of Community Health Nursing, BPKIHS, Dharan, Nepal \\ ${ }^{3}$ HOD and Professor, Department of Community Health Nursing, BPKIHS, Dharan, Nepal
}

*Corresponding Author

Sigdel R.

\author{
Article History \\ Received: 02.11.2020 \\ Accepted: 13.11 .2020 \\ Published: 09.02.2021
}

\begin{abstract}
Maternal health is a major focus of global public health. Over the years, nations have taken many initiatives, and the improved health indicators are a result of that. However, improvement in national data does not guarantee the improvement of health situation at sub-national level. Disparities have been seen on the basis of place of residence, education level of women, ethnicity, economic status etc. The aim of this study is to describe the maternal health indicators of selected wards of Barahachhetra municipality Sunsari. A descriptive cross-sectional design was used. Two hundred thirty three reproductive aged married women were taken from total enumeration. A pretested semi structured interview schedule was used to collect the data. Frequencies, percentage, mean and chi-squired test were used to analyze the data and the level of significance was at 0.05 . All the pregnant women had an at least one antenatal examination from a skilled provider. One third (33.2\%) of the respondents had become mother while they were adolescent. The contraceptive prevalence rate was 36.05\%, unmet need of FP was 53.21\%. Among family planning users, majority $(89.3 \%)$ used modern methods. Among the deliveries occurred within a year, $20.6 \%$ were home deliveries without skilled birth attendant. The use of family planning methods has statistically significant association with age and education level of women. There is a huge disparity in maternal health indicators specifically in the use of family planning and adolescent pregnancy while comparing with national level. Therefore these areas should be emphasized while preparing health related plan.
\end{abstract}

Keywords: Maternal health, adolescent pregnancy, family planning.

\section{INTRODUCTION}

Maternal health refers to the health of women before and during pregnancy, at childbirth and during the postpartum period. Antenatal care coverage, skilled attendant at birth, postnatal care, met need for contraception and maternal mortality ratio are some of the maternal health indicators described by WHO [1]. The aim of this study was to describe some of the maternal health indicators of selected wards of Barahachhetra municipality, Sunsari.

Maternal health is a major focus of global public health. Nations are always striving to achieve national targets. Many countries including Nepal have substantially progressed in improving the survival of mothers. Achievement of national targets cannot guarantee the same level of improvement at sub national level. Studies from China, India, Viet Nam and Indonesia revealed that these countries made substantial progress on maternal mortality rate, institutional deliveries, and contraceptive use at the national level however on a sub-national level they show wide disparities in health indicators [2]. In Nepal also health indicators such as percentage of adolescent pregnancy, unmet need of family planning, antenatal care coverage and institutional delivery varies among states $[3,4]$.

Additionally there are disadvantaged groups that do not benefit from development to the same extent, resulting in increasing inequity in health. Studies from India and Bangladesh show significant association of maternal education and family income with antenatal care coverage and hospital delivery [5, 6]. According to NDHS 2016 adolescence pregnancy is higher among illiterate $(28.6 \%)$ and who are under lowest wealth quintile $(14.8 \%)$ as compared to literate

Copyright (C) 2021 The Author(s): This is an open-access article distributed under the terms of the Creative Commons Attribution 4.0 International License (CC BY-NC 4.0) which permits unrestricted use, distribution, and reproduction in any medium for non-commercial use provided the original author and source are credited. 
(5\%) and highest wealth quintile (4.2\%) [3]. Disparity is also seen in use of modern family planning methods. Terai Dalit and Muslim are less likely (AOR: 1.9; 95\% CI: 1.4-2.7) to use modern family planning methods as compared to Brahmins/Chhetris and Newars [7].

Barahachhetra municipality ward no. 4 and 5 are rural areas, majority of the people are Tharu (Janajati) and Mushahar with low socio economic status $[8,9]$.

\section{Material ANd Methods \\ Research Design}

A descriptive cross-sectional design was used for the study. Data was collected from 30 May to 15 July 2019. It was a community based study and all the married women of reproductive age of Barahachhetra Municipality ward no. 4 and 5 were the study population. Study was conducted taking 233 reproductive aged married women. Respondents were interviewed by investigator herself using a self prepared pre tested structured questionnaire. Descriptive statistics such as frequencies, percentage, mean and SD were calculated and presented in tabular form. Inferential statistics (chi-square test) was used to show the association between dependent and independent variables taking $95 \%$ confidence interval.

\section{Pre-testing the Data Collection Tools}

Pre-testing was done in 25 reproductive aged married women of Barahachhetra Municipality ward no 6 to determine the feasibility of the study and appropriateness of the instrument and for the modification of the designed data collection tool.

\section{Ethical Consideration}

Ethical approval for the study was obtained from the institutional ethical review committee of BP Koirala Institute of Health Sciences with IRC no./484/075/076-IRC. A consent form was administered to the participants before data collection. Confidentiality was maintained throughout the study and the information collected was used only for the research purpose. Interview was carried out by maintaining privacy.

\section{Data Processing And Analysis}

Collected data were coded and entered in MS Excel 2007 and converted into SPSS 16 version for statistical analysis. Descriptive statistics such as frequencies, percentage, mean and SD were calculated and presented in tabular form. Inferential statistics (chi-square test) was used to show the association between dependent and independent variables taking $95 \%$ confidence interval.

\section{RESULTS AND DiSCUSSION}

\section{Characteristics of respondents}

A total of 233 reproductive aged women were enrolled in this study. The majority $(76.8 \%)$ of the respondent were in the age group 20-35 years. Mean age of the respondents was 28.88 years and standard deviation 7.22. Majority $(48.5 \%)$ were from janajati ethnicity followed by Brahmin/chhetri (39.9\%). Almost all (97.9\%) were Hindu. One third $(33.9 \%)$ of the respondents' education level was up to secondary. One fifth $(20.6 \%)$ of the respondents were illiterate. Almost all (90.1\%) were housewives. More than half $(57.1 \%)$ were in joint family. Similarly, $59.2 \%$ of the respondents had more than 5 members in their family. Nearly three quarter $(73.8 \%)$ of the respondents was below poverty line. The cut-off for poverty line is taken as income below $\$ 1.90$ per day.

Table-1: Socio-demographic characteristics of respondents $(n=233)$

\begin{tabular}{|l|l|l|l|}
\hline Characteristics & Categories & Frequency & Percentage \\
\hline \multirow{5}{*}{ Age } & $<20$ & 16 & 6.9 \\
\cline { 2 - 4 } & $20-35$ & 179 & 76.8 \\
\cline { 2 - 4 } & $>35$ & 38 & 16.3 \\
\cline { 2 - 4 } & Mean=28.88 yrs and S.D.=7.22 \\
\hline \multirow{5}{*}{ Caste } & Brahmin/chhetri & 93 & \\
\cline { 2 - 4 } & Dalit & 21 & 39.9 \\
\cline { 2 - 4 } & Janajati & 113 & 9.0 \\
\cline { 2 - 4 } & Others & 6 & 48.5 \\
\hline \multirow{4}{*}{ Religion } & Hindu & 228 & 2.6 \\
\cline { 2 - 4 } & Others & 5 & 97.9 \\
\hline \multirow{4}{*}{ Education } & Illiterate & 48 & 2.1 \\
\cline { 2 - 4 } & Primary & 73 & 33.9 \\
\cline { 2 - 4 } & Secondary & 79 & \\
\hline
\end{tabular}




\begin{tabular}{|l|l|l|l|}
\hline & Above secondary & 33 & 14.2 \\
\hline \multirow{2}{*}{ Occupation } & Hw & 210 & 90.1 \\
\cline { 2 - 4 } & Others & 23 & 9.9 \\
\hline \multirow{2}{*}{ Family type } & Joint & 133 & 57.1 \\
\cline { 2 - 4 } & Nuclear & 100 & 42.9 \\
\hline \multirow{2}{*}{$\begin{array}{l}\text { Total family } \\
\text { member }\end{array}$} & $\leq 5$ & 138 & 59.2 \\
\cline { 2 - 4 } $\begin{array}{l}\text { Per capita } \\
\text { income }\end{array}$ & $\begin{array}{l}\text { Above poverty } \\
\text { line }\end{array}$ & 61 & 40.8 \\
\cline { 2 - 4 } & $\begin{array}{l}\text { below poverty } \\
\text { line }\end{array}$ & 172 & 26.2 \\
\hline
\end{tabular}

\section{Reproductive history}

Regarding the reproductive history of the women (table 2) $6 \%$ of the respondents was pregnant at the time of data collection. One third (33.2\%) of the respondents had become mother before their $20^{\text {th }}$ birthday. After excluding 14 pregnant women, more than half $(61.6 \%)$ of the respondents do not use any type of family planning methods. Among family planning users, majority $(89.3 \%)$ used modern methods which include condom, Depo-Provera, implant, pills and sterilization. While asking the respondents about reason for not using family planning methods, more than half (59.3\%) of the respondents replied that their husband is not with them and $14.1 \%$ said the reason as fear of side-effects of family planning methods. Among respondents $14.6 \%$ had given birth of child within one year. Among them $79.4 \%$ and $20.6 \%$ were institutional and home deliveries respectively. Skilled birth attendant was not present in $100 \%$ of the home deliveries.

Table-2: Reproductive history of the respondents $(n=233)$

\begin{tabular}{|c|c|c|c|}
\hline Characteristics & Categories & Frequency & Percentage \\
\hline \multirow{2}{*}{ Currently pregnant } & No & 219 & 94.0 \\
\hline & Yes & 14 & 6.0 \\
\hline \multirow{2}{*}{ Age at first child birth $(n=211)$} & $<20 y r s$ & 70 & 33.2 \\
\hline & $\geq 20 \mathrm{yrs}$ & 141 & 66.8 \\
\hline \multirow{2}{*}{$\begin{array}{l}\text { Use of family planning methods } \\
(\mathrm{n}=219)\end{array}$} & No & 135 & 61.6 \\
\hline & Yes & 84 & 38.4 \\
\hline \multirow{2}{*}{ Types of FP methods $(n=84)$} & $\begin{array}{l}\text { Modern methods (condom, depo, implant, pills, } \\
\text { sterilization) }\end{array}$ & 75 & 89.3 \\
\hline & Traditional & 9 & 10.7 \\
\hline \multirow{9}{*}{$\begin{array}{l}\text { Reason for not using FP } \\
\text { methods }(n=135)\end{array}$} & My husband is not with me & 80 & 59.3 \\
\hline & Lactating within 6 months & 16 & 11.9 \\
\hline & Do not know about FP methods & 4 & 3.0 \\
\hline & Fear of side effects & 19 & 14.1 \\
\hline & No method is suitable for me & 1 & 0.7 \\
\hline & Fear of family members & 1 & 0.7 \\
\hline & No cooperation from husband & 3 & 2.2 \\
\hline & Diagnosed Infertility & 2 & 1.5 \\
\hline & Planning for pregnancy & 9 & 6.7 \\
\hline \multirow{2}{*}{ Child birth within one year } & No & 199 & 85.4 \\
\hline & Yes & 34 & 14.6 \\
\hline \multirow{2}{*}{ Place of delivery $(n=34)$} & Health center & 27 & 79.4 \\
\hline & Home & 7 & 20.6 \\
\hline \multirow{2}{*}{$\begin{array}{l}\text { Presence of SBA in home } \\
\text { delivery }(n=7)\end{array}$} & No & 7 & 100 \\
\hline & Yes & 0 & 0.0 \\
\hline
\end{tabular}

\section{Association between socio-demographic variables and use of family planning}

Study finding suggested that various relevant factors influence the use of family planning among the research participants (table 3). Finding depicted that there is an association of use of family planning with age and education level of women. 
Table-3: Association between selected socio-demographic variables and use of family planning

\begin{tabular}{|c|c|c|c|c|}
\hline Characteristics & \multirow{2}{*}{ Categories } & \multicolumn{2}{|c|}{ Use of FP } & Chi-square value \\
\hline \multirow{5}{*}{ Ethnicity } & & No & Yes & \multirow{4}{*}{0.754} \\
\hline & Brahmin/chhetri & 57 & 30 & \\
\hline & Dalit & 13 & 8 & \\
\hline & Janajati & 62 & 43 & \\
\hline & Others & 3 & 3 & \\
\hline & $<20$ yrs & 11 & 3 & \\
\hline Age & $20-35$ yrs & 111 & 56 & $<0.001$ \\
\hline & $>35 \mathrm{yrs}$ & 13 & 25 & \\
\hline & Below secondary & 58 & 56 & \\
\hline Education & Secondary and above & 77 & 28 & 0.001 \\
\hline & $\mathrm{Hw}$ & 122 & 74 & \\
\hline Occupation & Others & 13 & 10 & 0.593 \\
\hline & Joint & 78 & 48 & \\
\hline Type of family & Nuclear & 57 & 36 & 0.926 \\
\hline Total_famil & $\leq 5$ & 76 & 51 & 0520 \\
\hline lotal-tamily-member & $>5$ & 59 & 33 & 0.520 \\
\hline Per capita income & Above poverty line & 37 & 18 & 0221 \\
\hline & below poverty line & 98 & 66 & 0.321 \\
\hline
\end{tabular}

On the basis of collected data this study calculated the $\mathrm{MCH}$ indicators of the selected wards of the Barahachhetra municipality and found that the contraceptive prevalence rate was $36.05 \%$, unmet need of FP was $53.21 \%$, antenatal care coverage $\left(1^{\text {st }}\right.$ visit $)$ was $100 \%$, percentage of institutional delivery and percentage of delivery attended by SBA was $79.4 \%$.

\section{DiSCUSSION}

Barahachhetra Municipality has 9 wards. Ward number 4 and 5 are most remote wards. Mostly poor and illiterate Tharu (Janajati) reside in these two wards. The study aims to describe the maternal health indicators of these selected wards in relation to national level. To the best of our knowledge, this is the first study of this type in our context.

In this study $6 \%$ percent of the respondents were pregnant at the time of data collection. They were in different period of gestation. Therefore instead of information on ANC 4 visit only information on ANC 1 visit ( $1^{\text {st }}$ trimester) was collected. Cent percent of the pregnant women receive antenatal care (ANC 1 visit) from a skilled provider (doctor, nurse, and auxiliary nurse midwife). At national level two-thirds of women have their first ANC visit in the first trimester, as recommended.[3]. Similarly, the percentage of first antenatal visit during first trimester in India, Pakistan and Bangladesh have been recorded as $43.9 \%, 42.4 \%$ and $24.1 \%$ respectively [11]. The higher percentage of ANC in this study may be due to the provision of ANC-outreach clinic in their locality.

One in three respondents in this study had given first birth at the age of 15-19 years where as at national level one in five of adolescent girls become mothers or pregnant with their first child.[3] Similarly one third of adolescents in Bangladesh, 10\% in Indonesia and just 2\% in Maldives have either given birth or are pregnant [12]. The possible reason behind the higher percentage of adolescent pregnancy in this study may be due to early marriage and less education of girls.

In this study only $36.05 \%$ of the respondents use any type of family planning methods where as at national level, $53 \%$ of married women use any family planning method. Among family planning users, majority (89.3\%) used modern methods which include condom, depoprovera, implant, pills and sterilization. While asking the respondents about reason for not using family planning methods, more than half $(59.3 \%)$ of the respondents replied that their husband is not with them and $14.1 \%$ said the reason as fear of side-effects of family planning methods. That explains the reason for low contraceptive prevalence rate in this area.

The percentage of home delivery in this study $(20.6 \%)$ is lower than the national level (41\%). This may be due the distribution of packet of clothes (nyano Jhola) for mother and baby along with incentives by the nearby primary health center. Though the incentive for institutional delivery is available in government health centers all over the country the packet of clothes is not available in all health centers.

There was a statistically significant association between age of women and the use of family planning methods ( $p$ value<0.001). Similarly, the association between education level and the use of family planning methods was also statistically significant ( $\mathrm{p}$ value 0.001 ). This finding is similar to the findings of NDHS-2016 which states that the modern family planning use decreases with higher levels of education. Fifty-two percent of married women with no 
education use a modern method of family planning, compared to 34\% of women with SLC and above education [3]. Similarly study conducted in Ghana shows that educational level of respondents were associated with usage of family planning services $(\mathrm{P}<0.05)[13]$.

\section{Strength and limitations}

Our study has several strengths. First, it has attempted to describe the maternal health indicators of a poor and marginalized community otherwise it had been overlooked in the shadow of national-level indicators. Majority of the study search for the factors associated with the use of family planning but we have assessed the reasons for not using family planning methods. This will help the policy makers to address the unmet need.

Our study is not devoid of limitations. Though the number of respondents is 233 , in some cases subgroup analyses become difficult due to smaller number of sample in these subgroups. Some indicators such as adolescent fertility rate could not be calculated due to unavailability of denominator.

\section{CONCLUSION}

There is a huge disparity in $\mathrm{MCH}$ indicators of this area while comparing with national level. The maternal health indicators such as adolescent pregnancy, contraceptive prevalence rate, unmet need of family planning and percentage of institutional deliveries are needed to be addressed with due priority by municipal authorities. Social determinants of maternal health such as the age of first child birth and women's education need to be improved through social campaign.

The findings of the study help the municipal authority to identify the priority areas to improve the maternal health situation in that particular community. The results of the study are helpful to sensitize the provincial and federal authorities while calculating the national indicators to give an eye on the indicators of rural, marginalized and poor populations. The municipality should focus the programme of family planning to this community. A similar study can be carried out taking all the wards of the municipality.

\section{REFERENCES}

1. WHO. (2020). Recommendation 2: Health Health indicators. (n.d.). WHO; World Health Organization. Retrieved $\begin{array}{llll}\text { August } 30, & \text { 2020, }\end{array}$ https://www.who.int/woman_child_accountability/progress_information/recommendation2/en/.

2. Thomsen S., Hoa, D. T. P., Målqvist, M., Sanneving, L., Saxena, D., Tana, S., Yuan, B., \& Byass, P. (2011). Promoting equity to achieve maternal and child health. Reproductive Health Matters, 19(38), 176-182. https://doi.org/10.1016/S0968-8080(11)38586-2.

3. NDHS. (2016). key findings.pdf. (n.d.). Retrieved May 27, 2018, from https://nepal.unfpa.org/sites/default/files/pubpdf/NDHS\%202016\%20key\%20findings.pdf

4. DoHS Annual_Report_2072_73.pdf. (n.d.). Retrieved May 28, 2018, from http://dohs.gov.np/wpcontent/uploads/2017/06/DoHS_Annual_Report_2072_73.pdf

5. Barbhuiya, M. A., Hossain, S., Hakim, M. M., \& Rahman, S. M. (2001). Prevalence of home deliveries and antenatal care coverage in some selected villages. Bangladesh Medical Research Council Bulletin, 27(1), 19-22.

6. Viegas Andrade, M., Noronha, K., Singh, A., Rodrigues, C. G., \& Padmadas, S. S. (2012). Antenatal care use in Brazil and India: Scale, outreach and socioeconomic inequality. Health \& Place, 18(5), 942-950. https://doi.org/10.1016/J.HEALTHPLACE.2012.06.014

7. Mehata, S., Paudel, Y. R., Dotel, B. R., Singh, D. R., Poudel, P., \& Barnett, S. (2014). Inequalities in the use of family planning in rural Nepal. BioMed research international, 2014.

8. Social-economic-status-of-indigenous-peoples-of-nepal.pdf. (n.d.). Retrieved May 29, 2018, from http://www.indigenousvoice.com/uploads/books/social-economic-status-of-indigenous-peoples-of-nepal.pdf

9. Province_Chapter3.2_Mahottari.pdf. (n.d.). Retrieved May 29, 2018, from http://inseconline.org/en/wpcontent/uploads/2018/02/Province_Chapter3.2_Mahottari.pdf

10. Dixit, P., Khan, J., Dwivedi, L. K., \& Gupta, A. (2017). Dimensions of antenatal care service and the alacrity of mothers towards institutional delivery in South and South East Asia. PloS one, 12(7), e0181793.

11. Adolescent pregnancy. (n.d.). Retrieved October 11, 2020, from https://apps.who.int/iris/bitstream/handle/10665/204765/B5164.pdf?sequence=1\&isAllowed=y

12. Apanga, P. A., \& Adam, M. A. (2015). Factors influencing the uptake of family planning services in the Talensi District, Ghana. The Pan African Medical Journal, 20. https://doi.org/10.11604/pamj.2015.20.10.5301.

CITATION: Sigdel R et al (2021). Maternal Health Indicators of Selected Wards of Barahachhetra Municipality Sunsari Nepal. South Asian Res J Nurs Health Care, 3(1): 12-16. 